\title{
GUARDA COMPARTILHADA: A IMPORTÂNCIA DA PRESENÇA DOS PAIS COMO UM PROPÓSITO DE RESPONSABILIDADE DE AMBOS OS GENITORES.
}

\author{
Fernanda Maria Lacerda Oliveira, Rafael Correia Claro. \\ Universidade do Oeste Paulista- UNOESTE, Curso de Direito, Presidente Prudente, SP. E-mail: feerzinhalac@gmail.com
}

\begin{abstract}
RESUMO
O estudo aqui demonstrado tem o propósito de fazer uma breve análise acerca de um acontecimento comum na sociedade moderna, tal fato se caracteriza após a dissolução da esfera familiar, que ocasionará a necessidade de estabelecer a guarda do filho menor, podendo ser compartilhada entre os pais. Atualmente a dissolução do casamento vem sendo um fato bastante recorrente entre os casais em todo o mundo, desentendimentos, falta de compatibilidade de opiniões, traições, ou seja, são inúmeros os motivos que fazem o casal a dissolver o casamento, caso que, poderá haver um consenso entre os cônjuges ou ainda por vontade de apenas um.

Palavras-chave: casamento, dissolução, guarda, guarda compartilhada, responsabilidade.
\end{abstract}

SHARED GUARD: THE IMPORTANCE OF THE PRESENCE OF THE PARENTS AS A PURPOSE OF LIABILITY OF BOTH THE GENITORS.

\begin{abstract}
The purpose of this study is to give a brief analysis of a common event in modern society. This fact is characterized after the dissolution of the family sphere, which will cause the need to establish guardianship of the minor child and can be shared among the parents. Nowadays the dissolution of marriage has been a recurring fact among couples around the world, disagreements, lack of compatibility of opinions, betrayals, that is, there are innumerable reasons why the couple dissolve the marriage, in which case, there may be a consensus between the spouses or even for the sake of only one.
\end{abstract}

Keywords: marriage, breakup, guard, shared guard, responsibility. 


\section{INTRODUÇÃO}

Dentro de uma relação familiar, quando há a existência de filhos, ambos (pai e mãe) têm a responsabilidade de proteção, acompanhando todas as fases da vida da criança, desde de seus primeiros momentos de vida, seguindo na fase da infância, momento este onde o filho começa a fazer possíveis questionamentos aos pais, criando uma imensa imaginação para tentar entender certas coisas, mas na realidade a criança quando pequena, no seu desenvolvimento no que tange a sua personalidade e sua saúde mental, é carente de tomadas de decisões, não tem a possibilidade de entender o porquê de determinadas situações e isto, ou seja, este entendimento é extremamente importante para que na sua adolescência e na sua fase adulta ela se torne uma pessoa segura de si e de suas atitudes, carregando consigo uma base sólida ao que se refere a sua personalidade e integridade. E desse modo aos pais é imposto o dever de poder familiar, ou seja, tomar decisões na vida de seu (s) filho (s), seja em relação aos seus bens, ou ainda como agir em determinados momentos, ajudando e auxiliando o menor, independente se o casal mantém uma vida conjugal ativa ou se a relação se dissolveu por algum motivo.

Ao que se refere a criação dos filhos a mãe sempre foi responsável pelo cuidado, zelo e proteção da prole, no qual a interpretação que se tinha era de que a mulher já nascia com o dom de cuidar e de responsabilidade, já os homens não havia preparo algum, afinal eles nunca puderam brincar de bonecas, foram ensinados a ter o poder sobre a família, e as mulheres apenas instruídas a se apegarem as atividades domésticas. (DIAS, 2016)

Portanto, o presente trabalho tem por objetivo demonstrar dentro do contexto familiar, inclusive quando houver a dissolução da relação conjugal e com a guarda compartilhada a responsabilidade dos pais inerente a interesses de seus filhos menores, evidenciando a importância da presença paterna e materna na vida dos filhos para que haja um desenvolvimento psíquico e social satisfatório ao decorrer de seu crescimento.

\section{METODOLOGIA}

O estudo será desenvolvido por pesquisa bibliográfica, incluindo doutrinas que abordam sobre o tema.

$\mathrm{Na}$ composição deste trabalho será utilizado o método indutivo, ao que se refere as observações de casos da realidade para se chegar a uma conclusão. Além disso será empregado o método hipotético-dedutivo, onde a investigação científica visa construir e testar uma possível resposta ou solução do problema.

\section{RESULTADOS}

a) Entender o poder familiar dentro da relação conjugal;

b) Compreender as diretrizes a respeito da guarda compartilhada;

c) Considerar a guarda compartilhada como uma modalidade ao qual recai obrigações para ambos os genitores após a dissolução do matrimônio.

\section{VISÃO GERAL}

Diversas são as formas de família que vivem na atualidade, abrangendo novas formas, de modo que a família que prevalece é a dos pais e seus filhos.

Com as espécies e possibilidades de formas de famílias, o casamento é hoje um dos meios mais tradicionais para se iniciar uma família.

Podendo afirmar que a principal finalidade do casamento é "oriundo do amor do casal, baseado na igualdade de direitos e deveres dos cônjuges e na mútua assistência", art. 1.511 do CC.

Com o casamento resultam vários efeitos jurídicos, uma das responsabilidades dos pais para com os filhos deve ser exercida dentro casamento. De forma que tanto a mãe quanto o pai exercem o dever igualitário de zelar pelos filhos, se interessar e administrar situações 
pertencentes a vida do menor, indo mais adiante elucidar que mesmo após a dissolução do casamento, não há que se falar em término da responsabilidade sobre a criança por uma das partes.

Tema que se tornou bastante comum, devido à preocupação que se deve ter com a vida do menor, sua saúde mental e seu desenvolvimento como pessoa.

É de conhecimento de toda a sociedade de que a partir do momento que o casal resolve ter uma criança independentemente do modo em que ela vier à família, ambos deverão se responsabilizar pelas obrigações que se refere ao bem-estar do menor, optando sempre por atitudes que tragam reflexos positivamente para o filho.

Prevê a Constituição Federal de 1988 em seu art. 227. In Verbis:

É dever da família, da sociedade e do Estado assegurar à criança, ao adolescente e ao jovem, com absoluta prioridade, o direito à vida, à saúde, à educação, ao lazer, à profissionalização, à cultura, à dignidade, ao respeito, à liberdade e à convivência familiar e comunitária, além de coloca-los a salvo de toda forma de negligência, discriminação, exploração, violência, crueldade e opressão. (BRASIL, 1988).

Desse modo fica demonstrado que incumbe aos pais manter a criança em uma esfera familiar saudável, e priorizando sempre o seu bem-estar e os seus interesses.

O poder familiar pode ser exposto como direitos e obrigações inerentes aos pais, e exercido de forma de igualdade entre eles, para que possam juntos exercer o papel que os encargos que a lei determina, sempre levando como prioridade os interesses e tutela da criança. Os pais têm o direito de decidir ao que se refere a pessoa e aos bens do filho menor (DINIZ, 2015).

Com o fim da relação conjugal, surge com ela o direito e o dever de ambos, no sentido de partilha de bens, e a guarda dos filhos (quando houver).

O casal decide juntos em bom senso com quem deva ficar a criança, ou em casos mais complicados, que não há a compreensão de um ou dos dois, o assunto inevitavelmente chega à justiça, caso em que o magistrado analisará a situação, se atentando as argumentações de cada um, e decidindo sempre pelo lado que mais beneficia a criança.

\section{GUARDA COMPARTILHADA}

Hoje sabemos que existe a possibilidade de optar pela guarda compartilhada quando houver a dissolução do casamento ou ainda mesmo quando não houver tido uma convivência familiar entre os pais da criança, modalidade esta que assegura os laços entre pais e filhos, e ainda ambos os genitores são responsáveis pelo menor e pelas tomadas de decisões do filho ( MONTEIRO; SILVA, 2016).

Com a nova normatização, que assegura a ambos os genitores a responsabilidade simultânea ao que se refere aos interesses da prole e os direitos exercidos pelos pais inerentes ao poder familiar (CC, 1583 §1ํ.) e a determinação da guarda compartilhada com a distribuição do tempo de convívio de forma tranquila entre os pais (CC $1.583 \S 2^{\circ}$ ), um e outro permanecem com todo o complexo de deveres que advêm do poder familiar.

O objetivo da guarda compartilhada tem por evitar que um dos genitores se mantenha distante do filho após o divórcio, preservando a convivência entre o filho e seus genitores.

Como salienta DIAS, (2016, p 883):

Os fundamentos da guarda compartilhada são de ordem constitucional e psicológica, visando basicamente garantir o interesse da prole. Significa mais prerrogativas aos pais, fazendo com que estejam presentes de forma mais intensa na vida dos filhos. A participação no processo de desenvolvimento integral leva à pluralização das responsabilidades, estabelecendo verdadeira democratização de sentimentos.

Atualmente quando é necessário fazer a escolha da modalidade de guarda, na maioria dos casos, e por acordo dos próprios pais a criança tende a ficar com a mãe, e isso com o decorrer do 
tempo pode gerar e desencadear um distanciamento do pai ao que se refere a seus deveres e a importância que sua presença pode influenciar em um bom desenvolvimento do menor. Atualmente há milhares de casos em que se discute a guarda da criança, qual destino dará ao menor, caso em que em nenhuma situação deve ser afetado os direitos nem os deveres de ambos os genitores em relação à prole.

Segundo GAGLIANO; FILHO, (2016, p. 614):

$\mathrm{Na}$ esmagadora maioria dos casos, quando não se configura possível a celebração de um acordo, ou seja, uma solução madura e negociada, soa temerária a imposição estatal de um compartilhamento da guarda, pelo simples fato de que o mau relacionamento do casal, por si só, poderá colocar em risco a integridade dos filhos.

A guarda compartilhada é uma das possibilidades de criação do filho menor do casal em casos de divórcio, como já falado neste trabalho, ou até mesmo quando o casal nem chegou a se casar, tal possibilidade pode ser acordada entre as partes ou por determinação judicial quando há interesses contrários entre o casal (litígio).

Conforme o art. 1.583 do Código Civil, a guarda compartilhada é a responsabilização conjunta e o exercício de direitos e deveres do pai e da mãe que não vivam sob o mesmo teto, concernentes ao poder familiar dos filhos comuns.

Ela foi trazida pela Lei. № 13.058/2014, com a intenção de trazer benefícios ao menor, com o fato de que o pai e a mãe estejam presentes na vida do filho, proporcionando a ele afeto, felicidade e uma boa criação, e automaticamente tais benefícios acabam se estendendo aos pais, de maneira que terão uma maior participação na criação da criança ou do adolescente.

A finalidade é destinar o direito da criança e de seus dois genitores colocando uma barreira para que ocorre uma irresponsabilidade ocasionada pela guarda individual, como pode ser verificado pelas palavras de DIAS (2016, p. 883-884):

Compartilhar a guarda de um filho diz muito mais com a garantia de que ele terá pais igualmente engajados no atendimento aos deveres inerentes ao poder familiar, bem como aos direitos que tal poder Ihes confere. A guarda compartilhada deve ser tomada, antes de tudo, como uma postura, como o reflexo de uma mentalidade, segundo a qual pai e mãe são igualmente importantes para os filhos de qualquer idade e, portanto, essas relações devem ser preservadas para a garantia de que o adequado desenvolvimento fisiopsíquico das crianças ou adolescentes envolvidos venha a ocorrer.

Para a referida autora, a guarda compartilhada exige dos pais um desarmamento, um afastamento de rancores e frustações, e mesmo que os ressentimentos continuem, nem por isso deve-se deixar de lado a aplicação da modalidade que permite um convívio melhor que atende ao interesse dos filhos.

Portanto, é importante evidenciar que, mesmo que exista uma desavença entre os genitores, deverá os pais levar em consideração que ambos são de extrema importância na vida do filho, de forma que a criança e/ou o adolescente tenha um desenvolvimento satisfatório física e mental.

\section{CONCLUSÃO}

Com os pontos apresentados neste trabalho, é possível concluir que a guarda compartilhada quando imposta ou acordada entre as partes, tem como objetivo principal a responsabilidade de ambos na criação do filho menor, não somente isto, mas outro ponto valioso a ressaltar é que com essa modalidade de guarda é possível e mais simples o convívio e o elo entre a criança e os pais, mesmo após a extinção do matrimônio.

Vale ressaltar que, em todas as situações deverá ser analisado, a existência de bom relacionamento entre os pais, para que então seja cabível a guarda compartilhada, sempre atendendo as melhores condições para o menor. 


\section{REFERÊNCIAS}

- BRASIL. Código Civil. Lei no 10.406, 10 de janeiro de 2002. Do direito de família. Do direito pessoal. Do casamento. Disposições gerais. Disponível em: <http://www.planalto.gov.br/ccivil_03/leis/2002/l10406.htm>. Acesso em 28 mar. 2018.

- BRASIL. Constituição (1988). Constituição da República Federativa do Brasil. Brasília: Senado Federal, 1988.

- DIAS, MARIA BERENICE- Manual de direito das famílias. 11. Ed. Revista, atualizada e ampliada. De acordo com o novo CPC. - Revista dos Tribunais, 2016.

- DINIZ, MARIA HELENA- Curso de direito civil brasileiro. Volume 5: direito de família/ - 30. Ed. São Paulo: Saraiva, 2015.

- MALUF DABUS, C. A; E MALUF, D. F. R.C, A - Curso de direito de família. São Paulo: Saraiva, 2013.

- OLIVEIRA, A. M. E. M. et al. Normas e padrões para trabalhos acadêmicos e científicos da Unoeste. Presidente Prudente: Unoeste - Universidade do Oeste Paulista, 2015.

- STOLZE GAGLIANO, P.; E PAMPLONA FILHO, R. - Novo curso de direito civil. Volume 6: direito de família: as famílias em perspectiva constitucional/ -6. Ed. Ver. E atual. De acordo com o novo CPC. - São Paulo: Saraiva, 2016. 